Keywords: subdural haematoma; dengue haemorrhagic fever; haemorrhage

1 World Health Organisation. Dengue hemorrhagic fever: diagnosis, treatment and control. Geneva: World Health Organisation, 1986.

2 Sawaya R, Means ED. Acute spontaneous subdural hematoma. Surg Neurol 1984;21:363-6.

3 Hanakita J, Kondo A, Nishihara K, Yamamoto Y, Kinuta Y Spontaneous subdural hematoma in patients with advanced cancer report of two cases. Neurol Med Chir Tokyo 1985;25: 568-70.

4 Yanai Y, Kohno N, Mitsui T. Acute spontaneous subdural hematoma of arterial origin. Surg Neurol 1985;23:417-20.
5 Kanter R, Kanter M, Krisch W, Rosenberg G. Spontaneous posterior fossa subdural hematoma as a complication of anticoagulation. Neurosurgery 1984;15:241-2.

6 Bucci MN, Farhat SM. Metastatic adenocarcinoma of the prostate as a cause of subdural hematoma. $\mathcal{F}$ Urol 1986;135: 803-4.

7 Cave WS. Acute non-traumatic subdural hematoma of arterial origin. F Forensic Sci 1983;28:786-9.

8 Halstead SB. Dengue: hematological aspects. Semin Hematol 1982;19:116-9.

\title{
An unusual soft tissue tumour and peripheral eosinophilia
}

\author{
B Banerjee, M Nashi, G R Dixon
}

A 34-year-old woman presented with a painless swelling over her left deltoid region of about 3 weeks duration. There was no history of injury, recent infection or vaccination. The patient occasionally suffered from hay-fever and low-grade joint pain. Clinical examination revealed a firm ill-defined $10 \mathrm{~cm} \times 8 \mathrm{~cm}$ non-tender swelling over the posterior aspect of the left deltoid muscle without induration of the overlying skin. No restriction of joint movements was noted.

Initial laboratory studies revealed a normal total white cell count but an elevated eosinophilic count of $12 \%$. Erythrocyte sedimentation rate (ESR) was $19 \mathrm{~mm} / \mathrm{h}$. Serum biochemical profile was within normal limits. Rheumatoid factor and antinuclear antibodies were negative. Plain radiograph of the left shoulder only demonstrated soft tissue thickening over the deltoid region. Computed tomography (CT) of the left shoulder is shown in figure 1 .
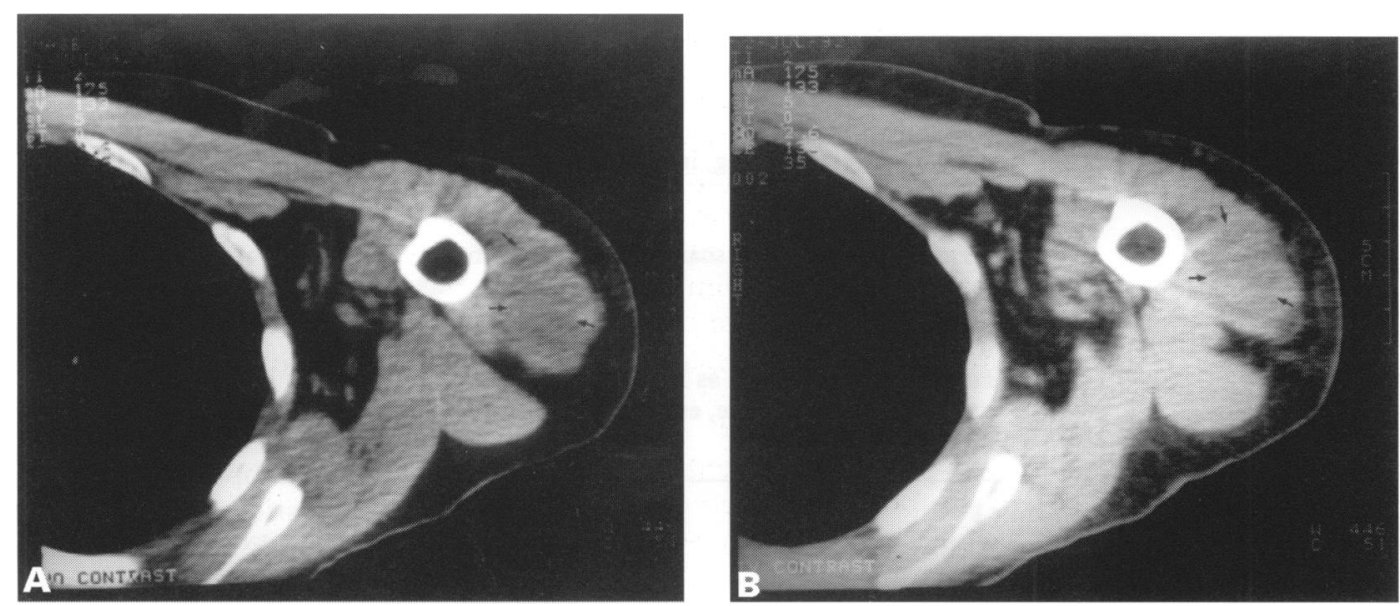

Figure 1 CT scans of the left shoulder, without (A) and with (B) intravenous contrast enhancement

Department of

Radiodiagnosis

B Banerjee

Department of

Orthopaedic Surgery

M Nashi

Department of

Pathology

G R Dixon

Accepted 21 January 1998

\section{Questions}

1 What do the CT scans show?

2 What is the most likely diagnosis?

3 What further investigation is required to confirm the diagnosis?

4 How is the condition managed? 


\begin{abstract}
Answers
QUESTION 1

The CT scans show an increase in volume of deltoid muscle within which a poorly marginated non-enhancing area is shown (marked with arrows). No rim enhancement is noted around the area with intravenous contrast, which suggests that it is unlikely to be an abscess cavity but rather a hypovascular soft tissue lesion.
\end{abstract}

\section{QUESTION 2}

Soft tissue swelling in the presence of peripheral eosinophilia should alert us to the possibility of eosinophilic fasciitis. However, conditions giving rise to peripheral eosinophilia and a multitude of soft tissue masses such as haematoma, inflammatory processes, and neoplasms, may coexist. Some common causes of peripheral eosinophilia are listed in box 1 .

\section{QUESTION 3}

Biopsy for histological diagnosis is essential. The histology in this case showed extensive infiltrate of eosinophilic polymorphs within the fascial plane and extending into skeletal muscle, characteristic of eosinophilic fasciitis (figure 2). The diagnosis of eosinophilic fasciitis is based on the clinical features, laboratory investigation, and full thickness biopsy of fascia and muscle of the affected areas.

\section{QUESTION 4}

The natural course of eosinophilic fasciitis is usually towards spontaneous improvement. Corticosteroids may help to accelerate recov-

\begin{tabular}{|l|}
\hline Causes of peripheral eosinophilia \\
\hline - drug sensitivity \\
allergy (eg, asthma) \\
- parasitic infestation (eg, intestinal worms) \\
- polyarteritis nodosa \\
- certain infections (eg, scarlet fever, erythema \\
multiforme) \\
- Loeffler's syndrome \\
tropical eosinophilia \\
- malignancy of any type, especially with \\
metastatic necrosis \\
\hline
\end{tabular}

Box 1

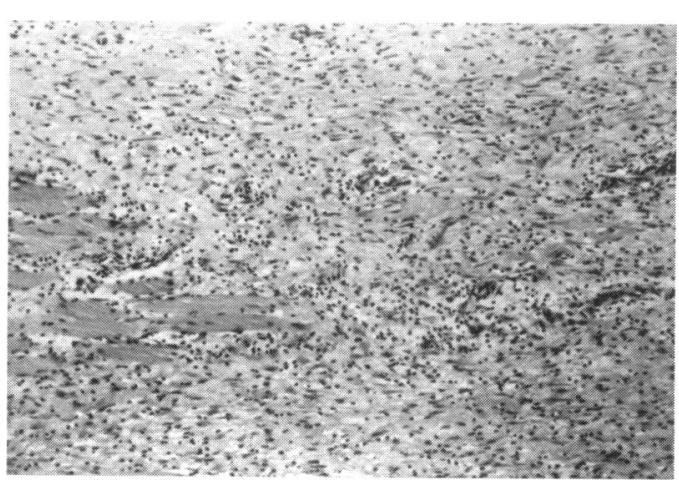

Figure 2 Histology of affected muscle

\section{Summary points}

- eosinophilic fasciitis is a systemic disease with diffuse fasciitis, primarily of extremities and rarely of trunk

- it is characterised by peripheral and tissue eosinophilia, increased ESR and hypergammaglobulinaemia

- it is usually a self-limiting disorder; cimetidine and corticosteroid therapy may accelerate remission

Box 2

ery, in contrast to scleroderma. Long-term therapy with cimetidine also appears to benefit many patients. Our patient was successfully treated with oral corticosteroids with progressive remission of the swelling and eosinophilia.

\section{Discussion}

Eosinophilic fasciitis, originally described by Shuliman in 1974, is a systemic disorder of unknown aetiology characterised by scleroderma-like skin changes, peripheral as well as tissue eosinophilia, hypergammaglobulinaemia, increased ESR and tender swelling of the extremities.

Although suggested by some as a variant of systemic sclerosis, it has now been recognised as a distinct clinical entity. ${ }^{1}$ Classically, the onset is rapid, following a prodromal stage of lassitude, low-grade pyrexia and muscle ache following an episode of extreme physical exertion. ${ }^{2}$ Soon, scleroderma-like skin changes develop, initially presenting as pitting oedema, followed by induration of the skin, and progressing to thickening of subcutaneous tissue and fascia causing limitation of joint movements and occasionally contractures. Other skeletal changes recorded, include arthralgia, arthritis, carpal tunnel syndrome, and low-grade myositis. ${ }^{3}$ Occasionally, visceral involvement has been documented. ${ }^{2}$ Recently, a separate clinical entity with remarkable resemblance to eosinophilic fasciitis has been widely reported following ingestion of L-tryptophan. ${ }^{4}$

Eosinophilia is detected in the early stage of the disease and may sometimes be an indicator of disease activity, although on rare occasions eosinophil count may be unremarkable. Diagnostic imaging of eosinophilic fasciitis has been poorly documented in the literature. Features of CT and magnetic resonance imaging are non-specific and described as generalised fascial thickening and areas of inflammatory changes in the underlying muscles. ${ }^{5}$

In our patient, the absence of prodromal symptoms, systemic manifestations of the disease, and onset of painless soft tissue swelling in a solitary site, led to diagnostic dilemma. We wish to draw attention to this rare clinical presentation of eosinophilic fasciitis which, to our knowledge, has not been documented in the literature and to suggest its inclusion in the differential diagnosis of soft tissue neoplasm, particularly in the presence of peripheral eosinophilia. 
Final diagnosis

Keywords: eosinophilic fasciitis; soft tissue tumour
1 Sibrack, LA, Mazur EM, Hoffman R, Bollet AJ. Eosinophilic fasciitis. Clin Rheum Dis 1982;812:443-54.

2 Maddison PJ. Editorial: Eosinophilic fasciitis. $\mathrm{Br} \mathcal{F}$ Rheumatol 1990;29:81-3.

3 Doyle JA. Eosinophilic fasciitis: extracutaneous manifestation and associations. Cutis 1984;34:258-61.
4 Roubehoff R, Cote T, Watson R, Levin M, Hockberg MC. Eosinophilia myalgia syndrome due to L-tryptophan ingestion. Report of 4 cases and review of the Maryland experience. Arthritis Rheum 1990;33:930-8.

5 Al-Shaikh A, Freeman C, Avrach L, Mckendry RJR. Use of magnetic resonance imaging in diagnosing eosinophilic fasciitis: report of two cases. Arthritis Rheum 1994;11:1602-8.

\title{
Acute anxiety - not always a psychiatrist's problem
}

\author{
S P L Meghjee, R J T Wilson
}

A previously fit 37-year-old man was a psychiatric admission, with acute onset of lethargy, hyperventilating, vomiting, and paraesthesia in his hands. He had a stressful job, with difficult financial and family circumstances. He was a strict Mormon Christian, and on direct questioning, denied taking any drugs. Except for hyperventilating, his initial examination was normal. An initial diagnosis of acute anxiety state was made, and he was treated with diazepam and chlorpromazine. Fourteen hours after admission, he developed fever of $38.7^{\circ} \mathrm{C}$ and became pale, clammy, sweaty and drowsy. He had no rash. His pulse was 150 beats $/ \mathrm{min}$ with blood pressure of $180 / 90 \mathrm{mmHg}$. Pulse oximetry showed an oxygen saturation of $89 \%$ on $60 \%$ inspired oxygen. His Glasgow Coma Scale was $14 / 15$ with no focal neurological signs. The rest of the examination was normal.

Despite being on maximal inspired oxygen via face mask, he deteriorated further with increasing tachycardia, labile blood pressure and falling saturation levels, and hence was formally anaesthetised, paralysed, and ventilated. Chest X-ray and electrocardiogram (ECG) rhythm strip are shown in figures 1 and 2 . His initial blood tests, and invasive monitoring results were as follows: haemoglobin $17.8 \mathrm{~g} / \mathrm{dl}$, white cell count $22 \times 10^{9} / 1$, platelets $407 \times 10^{9} / 1$, sodium $141 \mathrm{mmol} / 1$, potassium $4.6 \mathrm{mmol} / 1$, urea $11.4 \mathrm{mmol} / 1$, creatinine $227 \mathrm{mmol} / 1$, blood glucose $6.9 \mathrm{mmol} / 1$, adjusted calcium 2.40, INR 1.9, and activated partial thromboplastin time $86.2 \mathrm{~s}$ (control 27-38.0). Pre-ventilation arterial blood gases showed $\mathrm{pH} 7.378, \mathrm{pCO}_{2} 2.73 \mathrm{kPa}, \mathrm{pO}_{2} 11.7 \mathrm{kPa}$, bicarbonate $12.2 \mathrm{mmol} / 1$. and base excess of $-9.9 \mathrm{mmol} / 1$. Anion gap was 25 . Invasive monitoring revealed a central venous pressure of $7 \mathrm{cmH}_{2} \mathrm{O}$, pulmonary artery wedge pressure of $7 \mathrm{cmH}_{2} \mathrm{O}$ (14-18), cardiac index of $4.8 \mathrm{l} / \mathrm{min} / \mathrm{m}^{2}(2.5-4.2)$ and systemic vascular resistance of 346 dynes/ $\mathrm{cm}^{5}(800-1400)$.

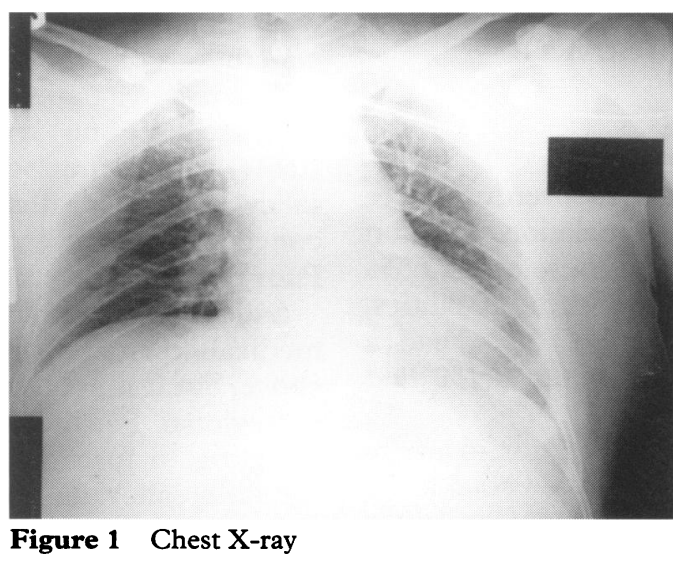

Departments of

Anaesthetics and

Intensive Care, York

District Hospital, York

YO3 $7 \mathrm{HE}, \mathrm{UK}$

S P L Meghjee

$\mathrm{R} J \mathrm{~T}$ Wilson

Accepted 21 January 1998

\section{Questions}

1 What abnormalities do the ECG rhythm strip and chest X-ray show?

2 What do the arterial blood gases show?

3 How would you interpret the invasive monitoring data?

4 What is the differential diagnosis?

5 What is the treatment? 